J. Dairy Sci. 98:2583-2595

http://dx.doi.org/10.3168/jds.2014-8640

(C) American Dairy Science Association ${ }^{\circledR}, 2015$.

\title{
The periparturient period is associated with structural and transcriptomic adaptations of rumen papillae in dairy cattle
}

\author{
M. A. Steele, ${ }^{*}{ }^{1}$ C. Schiestel, ${ }^{*}$ O. AlZahal, ${ }^{*}$ L. Dionissopoulos, ${ }^{*}$ A. H. Laarman, ${ }^{*}$ J. C. Matthews, $\ddagger$ \\ and B. W. McBride* \\ *Department of Animal and Poultry Science, University of Guelph, Guelph, N1G 2W1, Canada \\ †Department of Agricultural, Food and Nutritional Science, University of Alberta, Edmonton, T6G 2P5, Canada \\ ‡Department of Food and Animal Science, University of Kentucky, Lexington 40546-0215
}

\section{ABSTRACT}

The structural and functional adaption of the rumen epithelium during the transition period is largely undescribed. To characterize the adaptation of the rumen epithelium during transition, multiparous dairy cattle $(\mathrm{n}=12)$ fitted with rumen fistulas and fed a low-energy dry cow diet (1.37 Mcal $/ \mathrm{kg}$, net energy for lactation) were transitioned abruptly to a high-energy lactating cow diet (1.68 Mcal $/ \mathrm{kg}$, net energy for lactation) immediately after parturition. Rumen papillae were biopsied at $-3,+1$, and +6 wk relative to calving. The histology of morphology of the rumen papillae was evaluated under the light microscope and electron microscope, and mRNA profiling was performed using an Affymetrix GeneChip Bovine Gene 1.0 ST Array (Affymetrix, Santa Clara, CA). Data preprocessing was conducted using the robust multi-array average method, and detection of significant genes was conducted using ANOVA. Also, the Benjamini-Hochberg false discovery rate of 0.1 was applied. Microscopic examination of rumen papillae revealed an increase in epithelial desquamation during early lactation as sloughing scores increased from $1.7 \pm$ 0.2 at -3 wk to $4.1 \pm 0.3$ and $3.4 \pm 0.2$ at +1 and +6 wk, respectively. A total of 1,011 ( -3 vs. +1 wk) and 729 ( -3 vs. +6 wk) differentially expressed genes were identified (false discovery rate of $0.10, P<10^{-3}$, foldchange \pm 1.2 cut-off). A group of differentially expressed genes involved in desmosome assembly ( $D S G 1, C D S N)$, epidermal growth factor signaling ( $E G F R, E R E G)$, transforming growth factor $\beta$ signaling (TGFB1), and the insulin-like growth factor-axis (GHR, IGFBP2, $I G F B P 3, C T G F)$ was also validated using PCR. Gene network analysis found that EGFR, GHR, and TGFB1 were focal points of the top pathways, thereby supporting the importance of these regulatory genes to the adaptive response of rumen papillae in early lactation. The microscopic and transcriptomic changes in this

Received July 19, 2014.

Accepted December 22, 2014.

${ }^{1}$ Corresponding author: masteele@ualberta.ca study provide insight into the mechanisms responsible for the rapid rate of cellular and molecular adaptations of rumen papillae tissue during the transition period in dairy cattle. In conclusion, the experimental data support the hypothesis that rumen papillae adapt in early lactation by altering their gene expression patterns and, thus, their epithelial structure.

Key words: rumen epithelium, structure, gene expression, transition period

\section{INTRODUCTION}

It has become common practice in dairy production to abruptly transition cows from a low-energy to high-energy diet at parturition to compensate for the increased energy demand of lactation. The rumen is the focal point of energy digestion and absorption of the ruminant gastrointestinal tract as it is the site of microbial fermentation of carbohydrates to short-chain fatty acids (SCFA), which account for over $70 \%$ of the total ME available for the cow (Rémond et al., 1995). Shortchain fatty acids are absorbed by the rumen epithelium (RE). The RE overlays rumen papillae, the size of which can proliferate resulting in increased RE surface area and potential for nutrient absorption (Gäbel et al., 2002). For example, the RE responds to the increase in microbial fermentation end products by accelerating cellular proliferation to increase the surface area for SCFA absorption (Sakata and Tamate, 1978); as such, the rumen mass increases by $55 \%$ between $\mathrm{d} 14$ and 120 of lactation (Baldwin et al., 2004).

Concomitant with its increased mass and nutrient transport capacity, the RE must maintain the integrity of its stratified squamous epithelium to protect the host against the harsh environment of the rumen (Steele et al., 2011a). The mechanisms responsible for these adaptive changes are poorly understood. However, it is known that RE differentiation and proliferation is associated with growth factors of the IGF-axis (Shen et al., 2004; Steele et al., 2011a, 2012), epidermal growth factor family (EGF; Penner et al., 2011) and recently 
the transforming growth factor- $\beta$ family (TGFB; Connor et al., 2014). These studies evaluated gene expression of the RE in the developing ruminant or during a high grain challenge model. It would be extremely valuable to understand how the RE responds to the onset of parturition in concert with the abrupt change in dietary energy.

When dairy cows are fed rapidly fermentable dietary carbohydrate in early lactation they are more prone to develop the common digestive tract disorder ruminal acidosis (Plaizier et al., 2008). During the onset of ruminal acidosis, the structural integrity of the RE is compromised (Steele et al., 2011a), which is linked to the differential expression of various structural and SCFA metabolism genes (Penner et al., 2011; Steele et al., 2011b). In particular, genes associated with desmosomes (Steele et al., 2011a) and claudins (Liu et al., 2013) that are responsible for cellular adhesion have been differentially expressed in ruminants during high grain feeding. During ruminal acidosis, the structure of the RE can be compromised causing a pathological state; however, it is not known if similar changes occur due to the concert of dietary, physiologic, and metabolic changes in early lactation.

Despite recent progress in our understanding of how the $\mathrm{RE}$ adapts during various transition periods (weaning, high grain diets), the cellular and molecular events coordinating RE adaptations during the onset of lactation remain largely undescribed. Therefore, the primary aim of the study was to characterize the structural and functional genomic adaptations of whole rumen papillae during transition from a pre-partum low-energy diet to a postpartum, early lactation, high-energy diet transition period using microscopy and transcriptomic approaches. The overall hypothesis was that cell types of rumen papillae adapt in early lactation by altering their gene expression patterns and, thus, their structure and morphology. More specifically, it was hypothesized that the structure of the RE would be compromised during early lactation. With regard to gene expression, it was hypothesized that expression of growth factors (IGF-axis, EGF, and TGF) and cell adhesion genes (desmosomal cadherins, claudins) would be modulated during the transition period from relatively low intake of a low-energy prepartum diet to that of high intake of a high-energy diet after parturition and during early lactation.

\section{MATERIALS AND METHODS}

\section{Animals, Experimental Treatments, and Feeding}

All procedures before the start of the trial were conducted in accordance with the Canadian Council on
Animal Care (1993) and approved by the University of Guelph Animal Care Committee. The experiment was previously described by Dionissopoulos et al. (2014), which focused on describing the changes of immune genes in rumen tissue during the transition period. In brief, 12 Holstein dairy cows consisting of one-half primiparous (644 $\pm 13 \mathrm{~kg}$ of BW, mean $\pm \mathrm{SD})$ and the other half multiparous $(760 \pm 10 \mathrm{~kg}$ of $\mathrm{BW}$, mean \pm SD) were used in this study. Each cow was fitted with a rumen fistula during the dry period before their first or second lactation as described by Duffield (1999), and housed in a tie-stall facility at the Elora Dairy Research Station for the duration of the experiment (University of Guelph, Guelph, Ontario, Canada). Throughout their lactation, the cattle had unlimited access to water, were milked twice daily in their stalls at 0600 and 1600 $\mathrm{h}$, and allowed to exercise for $2 \mathrm{~h}$ starting on $0800 \mathrm{~h}$.

The prepartum diet consisted of a TMR fed once daily $(0700 \mathrm{~h})$ and the lactating cattle received a lactation TMR twice daily (0700 and $1500 \mathrm{~h}$ ), both balanced based to meet nutrient guidelines (NRC, 2001). The prepartum diet consisted of $45 \%$ corn silage, $11 \%$ alfalfa silage, $27 \%$ straw, and $18 \%$ protein supplement on a DM basis (TMR composition; $45 \%$ DM, $13 \%$ CP, $31 \%$ ADF, $46 \%$ NDF, 34\% NFC, $18 \%$ starch, 1.37 Mcal/ $\mathrm{kg}$ of $\mathrm{NE}_{\mathrm{L}}$ ). For the lactating cow diet, the same corn silage $(26 \% \mathrm{DM})$, alfalfa silage $(26 \% \mathrm{DM})$, and straw $(6 \% \mathrm{DM})$ were used with a lactating cow supplement (21\% DM) along with additional high-moisture corn to increase energy density of the diet (TMR composition; $45 \%$ DM, 16\% CP, $23 \%$ ADF, 34\% NDF, $43 \%$ NFC, $22 \%$ starch, $1.68 \mathrm{Mcal} / \mathrm{kg}$ of $\mathrm{NE}_{\mathrm{L}}$ ). Immediately after parturition all cows were abruptly transitioned from the dry cow diet to the lactating cow diet. To achieve ad libitum intake for both diets, the amount of offered feed was adjusted daily with the target of having a minimum of $5 \mathrm{~kg}$ of feed refusals/day per cow (as-is basis).

\section{Rumen Papillae Biopsies}

Rumen papillae were biopsied from each of the 12 cows on 3 different occasions during the periparturient period: at $3 \mathrm{wk}$ prepartum, $1 \mathrm{wk}$ postpartum, and 6 wk postpartum. The papillae were collected from the ventral sac of the rumen as it has been determined to be the site with the highest capillary blood flow per unit weight mucosa of any location within the rumen (Von Engelhardt and Hales, 1977). In brief, the ventral sac was partially evacuated to facilitate the retraction of the ventral sac to the fistula. Sterile surgical scissors were used to clip approximately $200 \mathrm{mg}$ of rumen papillae that were quickly washed 20 times in ice-cold PBS. After washing, papillae were placed in room 
temperature RNAlater (Qiagen, Missassauga, ON, Canada) or fixatives, respectively, for transcriptomic and microscopic analysis (described below). Biopsies were taken at $1000 \mathrm{~h}$, and rumen fluid used for $\mathrm{pH}$ and SCFA determination were also collected at this time (Dionissopoulos et al., 2014).

\section{Microscopy}

Five papillae per cow per time point were prepared for light microscopy histomorphometric analysis using methods previously described by Steele et al. (2011a). All papillae were embedded longitudinally in paraffin wax (Odongo et al., 2006) to maximize the surface area to view each papillae (base to tip in same slide). Formalin-fixed, paraffin-embedded papillae were sectioned at a 4- $\mu \mathrm{m}$ thickness, stained with hematoxylin and eosin, and mounted for histological analysis. The microscopist was blinded to treatment during the examination of rumen papillae. Images of all papillae were taken using an Olympus BX60 (Center Valley, PA) light microscope at $250 \times$ magnification for strata measurements from base to tip. Micrographs of the base, middle, and tip of the rumen papillae were used for the histomorphometric analysis (3 images per papillae). ImageJ Plus software (Media Cybernetics, Bethesda, MD) was employed to measure the thickness of the living strata (basale, spinosum, and granulosum) and the corneum as previously described (Steele et al., 2011a; Steele et al., 2012). For each papillae, 36 measurements of the living strata and the corneum were taken, equating to 180 measurements of RE thickness per cow per time point (5 papillae per cow). The mean value for all rumen papillae histomorphometric measurements of each cow was used in the statistical evaluation.

In addition to measurements of cell layers, the degree of desquamation was also scored using the same Olympus BX60 light microscope and at 50× magnification. Three technicians were trained to score the degree of sloughing in rumen papillae using representative samples from the study. A score of 1 indicated nil to minor desquamation, a score of 3 indicated minor desquamation of the corneum, and a score of 5 indicated severe desquamation (Supplemental Figure S1; http:// dx.doi.org/10.3168/jds.2014-8640). Three technicians were blinded to treatment and scored 5 papillae per cow per week using the common sloughing criteria. The mean score from all technicians from each slide for each cow was used in the analysis.

Additional papillae were prepared for scanning electron microscopy using methodology reported by Graham and Simmons (2005). After washing in PBS, papillae were immediately fixed in $2 \%$ glutaraldehyde for 24 $\mathrm{h}$, postfixed for $1 \mathrm{~h}$ in $1 \%$ osmium, and dehydrated in a series of ethanol solutions. Moisture was removed from the sample using a critical-point drying using liquid $\mathrm{CO}_{2}$ as the medium. The sample was mounted, coated with gold, and surface morphology of the samples was then examined using scanning electron microscopy (Hitachi S-570, Hitachi Technologies, Tokyo, Japan). A total of 3 rumen papillae were observed per cow per week.

\section{RNA Isolation, Microarrays, Network Analysis}

Total RNA was isolated from approximately 100 mg of papillae tissue per cow using an RNeasy Midi Kit (Qiagen, Mississauga, Canada). The 260:280 ratio was determined for all samples to be between 1.9 and 2.1 and the concentrations were determined using a NanoDrop (ND-1000, NanoDrop Technologies, Wilmington, DE). Isolated RNA was treated with DNase (Invitrogen, Burlington, Canada), and the quality was assessed using an Agilent 2100 Bioanalyzer (Agilent Technologies Inc., Palo Alto, CA) and RNA 6000 Nano kit (Caliper Life Sciences, Mountain View, CA). The mean RNA integrity number for the samples was $9.1 \pm$ 0.2 for microarray and $8.6 \pm 0.2$ for PCR.

Microarrays were used to screen the mRNA/ transcriptome expression patterns of candidate gene families related to growth factors (TGFB, EGF, and IGF-axis) and cell adhesion (desmosomes, occludins) in papillae tissue. One microarray per cow was used to assess effects of $-3,+1$, and +6 wk treatments (n $=12$ cows $/$ treatment). Microarray analysis was conducted at the University of Kentucky Core Microarray Facility using a bovine Affymetrix GeneChip array (Bovine Gene 1.0 ST Array, Affymetrix, Santa Clara, CA). After preparing cDNA, it was labeled using an Encore Biotin Module k (part no. 4200, NuGEN, San Carlos, CA). The labeled products were hybridized to arrays according to the NuGEN Technologies protocol (Steele et al., 2013). Stringent and nonstringent wash buffers were used to wash the arrays followed by staining with streptavidin phycoerythrin and antibody solutions, and scanning using an Affymetrix Genearray scanner.

Ingenuity Pathway Analysis (IPA) V7.5 (Ingenuity, Redwood City, CA; http://www.ingenuity.com/) software licensed by the University of Kentucky was used to perform the network analysis of DEG. The knowledge base of IPA was used for the DEG enrichment analysis, and network analysis statistical calculations were completed between experimental time points. Generation of networks of DEG was based on their connectivity within IPA, and a network score was assigned to each gene network based on the hypergeometric distribution (Steele et al., 2011b). 


\section{Quantitative Real-Time PCR}

To confirm the mRNA expression of candidate genes identified from the microarray analysis, quantitative real-time PCR (qPCR) was performed. Primers for structural genes (DSG1, desmoglein 1; $\boldsymbol{C D S N}$, corneodesmosin), growth factor associated genes ( $\boldsymbol{T} \boldsymbol{G F B 1}$, transforming growth factor $\beta 1 ; \boldsymbol{E} \boldsymbol{G F R}$, epidermal growth factor receptor; $\boldsymbol{E R} \boldsymbol{E} \boldsymbol{G}$, epiregulin; $\boldsymbol{I} \boldsymbol{G F B P 2}$, IGF binding protein 2; IGFBP3, IGF binding protein 3; $\boldsymbol{C T} \boldsymbol{T} \boldsymbol{F}$, connective tissue growth factors) are presented in Table 1. After RNA isolation and quality assessment (described above), samples ( $\sim 800$ ng each) were reverse-transcribed using the High-Capacity cDNA reverse transcription kit (Life Technologies, Burlington, ON, Canada). The PerfeCTa SYBR Green (Quanta Bioscience, Mississauga, ON, Canada) was used to perform qPCR in duplicate using an ABI StepOnePlus Real Time Systems (Life Technologies Inc., Mississauga, ON, Canada). The sequences, $\mathrm{R}^{2}$, standard curve slope, and primer efficiencies of primers are presented in Table 1. Exon-spanning primers for target genes were designed using Primer Blast as described by Ye et al. (2012) from bovine sequences listed in GenBank (National Center for Biotechnology Information, Bethesda, MD). Dissociation curves were generated at the end of amplification to verify the presence of a single product. The standard curve method with 5 dilutions ranging from 1:5 to 1:3,125 was used to calculate the efficiency of qPCR amplification. The efficiency of qPCR amplification for each gene was calculated using the standard curve method $\left(\mathrm{R}^{2}\right.$, standard curve slope, and primer efficiencies of primers are presented in Table 1). Three common bovine housekeeping genes were tested before $\beta$-actin $(\boldsymbol{B} \boldsymbol{A} \boldsymbol{C T})$ was determined to be a suitable for this study [standard deviation $=0.15$, Ct (cycle threshold); CV 0.45, \% Ct] compared with Beta-2 microglobulin and glyceraldehyde 3-phosphate dehydrogenase (Pfaffl, 2001). Consequently, all qPCR data were adjusted to $B A C T$ expression values.

\section{Calculations and Statistical Analysis}

For microarray analysis, the data preprocessing was conducted using the robust multi-array average method, and detection of differentially expressed genes (DEG) was determined using ANOVA generated by Partek Software, version 6.3 (Partek Inc., St. Louis, MO). A Benjamini-Hochberg false discovery rate of 0.1 was applied, and the model included the fixed effect of time. Individual variables were analyzed using the mixed-model procedure with repeated measures in SAS (SAS Institute Inc., 2004) to contrast histological data with cow as the observational unit. The model included the fixed effect of time and the random effect of cow, and then the best-fitting covariance structure from each variable was determined to compare time points. Candidate genes uncovered from the microarray analysis (methodology described in previous section) were validated by qPCR. To analyze mRNA expression, qPCR data were transformed to obtain a perfect mean of 1.0 at -3 wk relative to parturition. The inverse of $\mathrm{qPCR}$ efficiency raised to delta $\mathrm{Ct}$ was used to calculate the abundance of genes (Pffafl, 2001). Expression data were presented as fold change relative to the prepartum $(-3$ wk; Xue et al., 2010). Gene expression data also were analyzed by the same mixed-model procedure with repeated measures to determine significance. Polynomial orthogonal contrasts were used to compare all variables, and significance was declared when $P<0.05$.

\section{RESULTS}

\section{Histology and Morphology}

Light and scanning electron microscopy of rumen papillae biopsied at $-3,+1$, and +6 wk relative to calving are displayed in Figure 1. Microscopy revealed histological and morphological changes between rumen papillae harvested at -3 wk compared with +1 and +6 wk in lactation. The rumen papillae harvested in the prepartum period displayed a stratified squamous epithelium with strong delamination between basale, spinosoum, granulosum, and corneum cells (Figure 1A, D, G). Few lesions were evident and the living cells of the stratified squamous epithelium were closely connected with each other. Cells were strongly anchored to one another with tight adhesion. The corneum displayed minimal desquamation both histologically and morphometrically (Figure 1D, G).

The onset of lactation was marked by an alteration in rumen papillae histology and morphology from -3 wk before parturition to +1 wk (Figure 1B, E, H) and +6 wk (Figure 1C, F, I) of lactation. The delamination between specific strata of the RE was decreased, especially between the granulosum and the corneum. Several intermediate cell types, all at different stages of cellular degradation, are found between granular cells and the fully differentiated keratinocytes (Figure 1E, F). The rumen papillae surface morphology from -3 wk to +1 and +6 wk became more rigid and the outermost layer of keratinized cells appeared to be loosely attached (Figure 1G, H, I). The corneum showed signs of excessive desquamation during the onset of lactation supported by an increase $(P<0.01)$ in sloughing scores of rumen papillae from $1.7 \pm 0.2$ at -3 wk to $4.1 \pm 0.3$ and $3.4 \pm 0.2$ at +1 and $+6 \mathrm{wk}$, respectively. In spite of the excessive sloughing and cellular differentiation, 
Table 1. Primers for quantitative real-time PCR

\begin{tabular}{|c|c|c|c|c|c|}
\hline Gene & Gene name & Gene ID & Primers & $\begin{array}{l}\text { Amplicon } \\
\text { size }\end{array}$ & Eff $\%^{1}$ \\
\hline$B A C T$ & Beta actin & XM_002696364.1 & $\begin{array}{l}\text { F438-CGTGAGAAGATGACCCAGATCA } \\
\text { R563-TCACCGGAGTCCATCACGAT }\end{array}$ & 87 & 93.5 \\
\hline$E G F R$ & Epidermal growth factor receptor & NM_001037319.1 & $\begin{array}{l}\text { F137-TGAAAAACAGTGCAAGGCCG } \\
\text { R294-ACGACTGAAGTTCTGGCAGG }\end{array}$ & 157 & 93.9 \\
\hline$E R E G$ & Epiregulin & NM_001075549 & $\begin{array}{l}\text { F855-GCGACAAGAAGGGCTTTTACAA } \\
\text { R936-TATCCACACACCAGCAGAAACC }\end{array}$ & 81 & 97.6 \\
\hline$I G F B P 2$ & IGF binding protein 2 & NM_001105327 & $\begin{array}{l}\text { F701-CAAACAGTGCAAGATGTCTCTGA } \\
\text { R764-GCTATGGTTTACTGCATCCGC }\end{array}$ & 63 & 94.6 \\
\hline IGFBP3 & IGF binding protein 3 & NM_001075549 & $\begin{array}{l}\text { F855-GCGACAAGAAGGGCTTTTACAA } \\
\text { R936-TATCCACACACCAGCAGAAACC }\end{array}$ & 81 & 95.7 \\
\hline$I G F B P 5$ & IGF binding protein 5 & BC102850 & $\begin{array}{l}\text { F143-CTACAAGAGAAAGCAGTGCAAACC } \\
\text { R209-TCCACGCACCAGCAGATG }\end{array}$ & 67 & 94.6 \\
\hline$T G F B 1$ & Transforming growth factor beta 1 & NM_177497 & $\begin{array}{l}\text { F137-TGAGCCAGAGGCGGACTACT } \\
\text { R294-TGCCGTATTCCACCATTAGCA }\end{array}$ & 103 & 101.2 \\
\hline$C T G F$ & Connective tissue growth factor & NM_001037319.1 & $\begin{array}{l}\text { F137-AGCTGAGCGAGTTGTGTACC } \\
\text { R294-TCCGAAAATGTAGGGGGCAC }\end{array}$ & 157 & 119.0 \\
\hline$D S G 1$ & Desmoglein 1 & NM_001013004 & $\begin{array}{l}\text { F775-AGACAGAGAGCAATATGGCCAGT } \\
\text { R863-TTCACACTCTGCTGACATACCATCT }\end{array}$ & 60 & 100.3 \\
\hline$C D S N$ & Corneodesmosin & NM_001075549 & $\begin{array}{l}\text { F855-TTGTTGCCCATGGTGGTTCT } \\
\text { R936-GGAGCTCGATGCACCTTGTA }\end{array}$ & 81 & 92.1 \\
\hline
\end{tabular}


-3 weeks
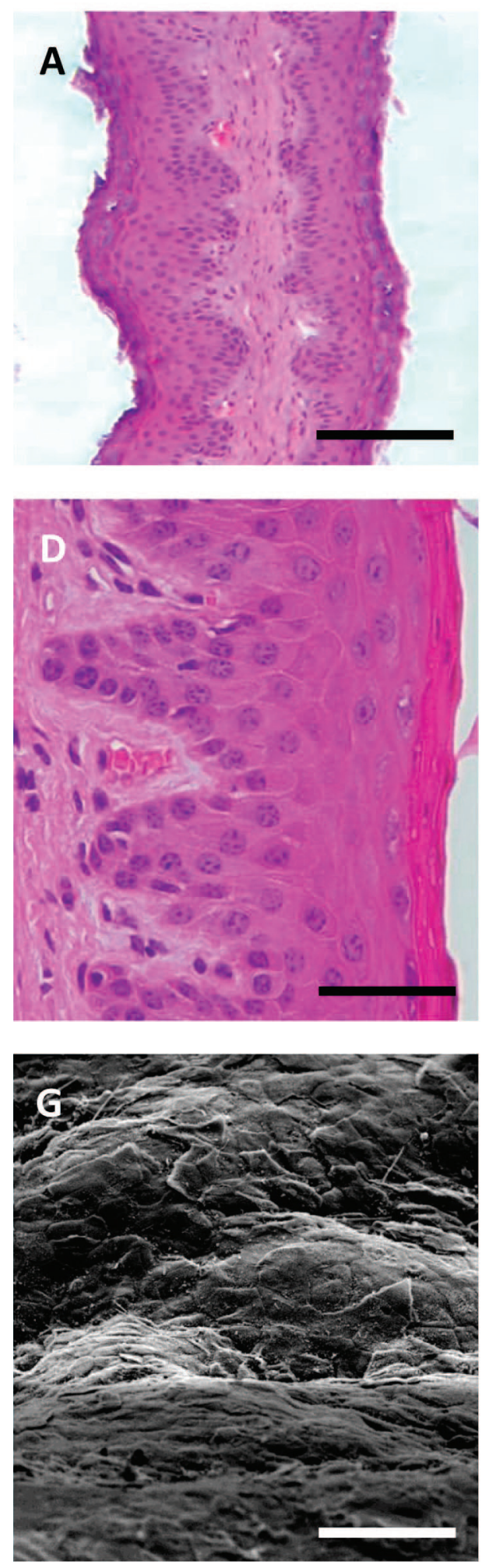

+1 week
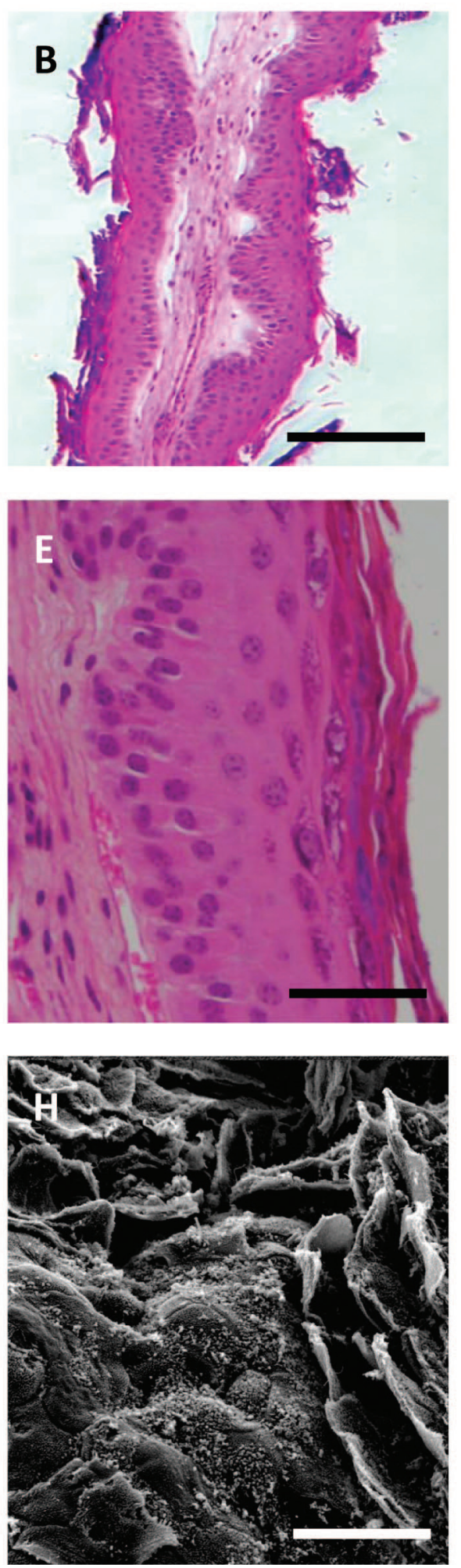

+6 weeks
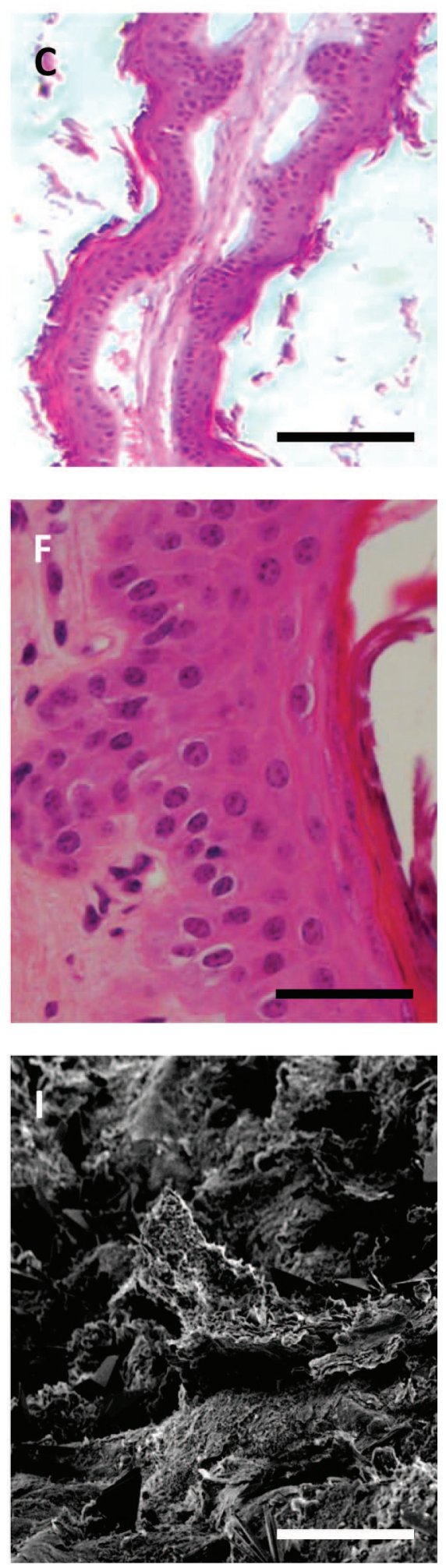

Figure 1. Representative light and electron micrographs of rumen papillae 3 wk before parturition ( -3 wk; A, D, and G), 1 wk after parturition $(1 \mathrm{wk} ; \mathrm{B}, \mathrm{E}$, and $\mathrm{H})$, and 6 wk after parturition $(+6 \mathrm{wk} ; \mathrm{C}, \mathrm{F}$, and I). Black bar, A, B, C = $300 \mu \mathrm{m} ; \mathrm{black}$ bar, D, E, F = 30 $\mu \mathrm{m}$; white bar, $\mathrm{G}, \mathrm{H}, \mathrm{I}=30 \mu \mathrm{m}$. Color version available online. 
the $\mathrm{RE}$ during lactation displayed minimal lesions with cohesive strata. The measurements of total epithelial thickness in all of the images of the middle and base of the rumen papillae did not change when the effect of week was analyzed $(P>0.05)$. However, the measurements of total epithelial thickness on the images of rumen papillae tips increased $(P<0.05)$ from $-3 \mathrm{wk}$ $(103.5 \pm 5.9 \mu \mathrm{m})$ to $+1 \mathrm{wk}(128.0 \pm 10.9 \mu \mathrm{m})$ and +6 wk $(124.9 \pm 7.7 \mu \mathrm{m}$; Supplemental Figure S2; http:// dx.doi.org/10.3168/jds.2014-8640). No difference $(P>$ $0.05)$ in corneum thickness was detected between weeks or sites of the papillae.

\section{Microarray, Pathways, and Network Results}

The transcriptomic analysis was focused on comparing the dry period to the immediate onset of lactation $(-3$ vs. $+1 \mathrm{wk})$ and at $6 \mathrm{wk}$ into lactation $(-3$ vs. +6 wk). A total of 1,011 DEG were identified from the -3 vs. +1 wk comparison; 527 were upregulated and 484 were downregulated from the dry period to the first week of lactation (Supplemental Table S1; http:// dx.doi.org/10.3168/jds.2014-8640). The comparison between -3 and +6 wk yielded 729 DEG (522 upregulated, 207 downregulated; Supplemental Table S2; http://dx.doi.org/10.3168/jds.2014-8640). From the DEG list, 26 genes were members of the predetermined growth factors and cell adhesions genes of interest (Supplemental Table S3; http://dx.doi.org/10.3168/ jds.2014-8640). Most relevant to the specific hypothesis being tested were the differential expression of $D S G 1$ and coneodesmosin ( $>+3$-fold change). Furthermore, marginal reductions $(P<0.1 ;< \pm 1.3$-fold change) were observed in the expression of claudins 12,23 , and 7 and increases of claudin 17 and occludin $(< \pm 1.3$-fold change). For growth factors, the most relevant genes to the hypothesis being tested include EGFR, EREG, growth hormone receptor $(\boldsymbol{G H R})$, and TGFB1 (Supplemental Table S3; http://dx.doi.org/10.3168/jds.20148640). With respect to the IGF-axis, IGF1 increased $(P<0.05 ; 1.3$-fold change $)$ from -3 to $+6 \mathrm{wk}$, whereas $I G F 1 R$ was reduced $(P<0.1 ; 0.8$-fold change). Alterations in IGFBP expression such as IGFBP2, IGFBP3, $I G F B P 5$, and $I G F B P 7$ were detected from -3 wk to +1 and +6 wk. Interestingly, TGFB2 gene expression also increased $(P<0.1 ; 1.3$-fold change $)$ from -3 to +6 wk. From the 26 genes identified to be differentially expressed, 16 of them held a similar expression profile at wk 6 . These results indicate that $\mathrm{RE}$ signaling in the first week of lactation is maintained for up to 6 wk into lactation.

For the early lactation comparison ( -3 vs. +1 wk), 802 of the 1,011 DEG could be mapped to a known molecular function for network analysis using IPA. A total of 25 networks were identified by IPA: 3 of which had a score of 41 with over 31 focus genes (focus genes are defined as DEG that directly interact with other genes in the Ingenuity global molecular network, and a network score is derived from a $P$-value and indicates the likelihood of the focus genes in a network being found together due to random chance). The first network had a score of 53 with 35 focus genes and revealed links between DNA replication, recombination, and repair, carbohydrate metabolism, and small molecule biochemistry with TGFB1 as a focal gene (Supplemental Figure S3; http://dx.doi.org/10.3168/ jds.2014-8640). The second highest network with a score of 42 and 31 focus genes was involved in nutritional disease, metabolic disease, and neurologic disease, which included $G H R$ as a focal gene in the network (Supplemental Figure S4; http://dx.doi. org/10.3168/jds.2014-8640).

For the 6 -wk lactation comparison ( -3 vs. $+6 \mathrm{wk}$ ), 670 of the 749 DEG could be mapped to a known molecular function for network analysis using IPA. Furthermore, a total of 40 networks were identified by IPA; 2 of these had a score of 40 with more than 28 focus genes. The first network had a score of 47 with 31 focus genes and revealed links between cellto-cell signaling and interaction skeletal and muscular system development and function, tissue development, and TGFB1 was again the focal point (Supplemental Figure S5; http://dx.doi.org/10.3168/jds.2014-8640). The second network had a score of 40 and 28 focus molecules with top functions of protein synthesis, lipid metabolism, and small molecular biochemistry, which included both EGFR and GHR (Supplemental Figure S6; http://dx.doi.org/10.3168/jds.2014-8640).

\section{$q P C R$}

The results of the qPCR validation of candidate genes that were differentially expressed between -3 and $+1 \mathrm{wk}$, and -3 and $+6 \mathrm{wk}$ is presented in Figure 2. The correlation coefficient between fold changes calculated by microarray and PCR data was high ( $\mathrm{r}$ $=0.76 ; P<0.05)$. As shown in Figure 2A, the structural genes $D S G 1$ and $C D S N$ displayed clear increase during early lactation. Correspondingly, TGFB1 and $C T G F$ increased during the onset of lactation but with lower fold changes (Figure 2B). The EGF growth factor $E R E G$ was upregulated, whereas $E G F R$ and $G H R$ were downregulated (Figure $2 \mathrm{C}$ ). The relative expression of $I G F B P 3$ was lower whereas the expression of IGFBP2 was higher during the onset of lactation (Figure 2D). An illustrative representation describing candidate gene expression in the context of cellular growth is displayed in Figure 3. 

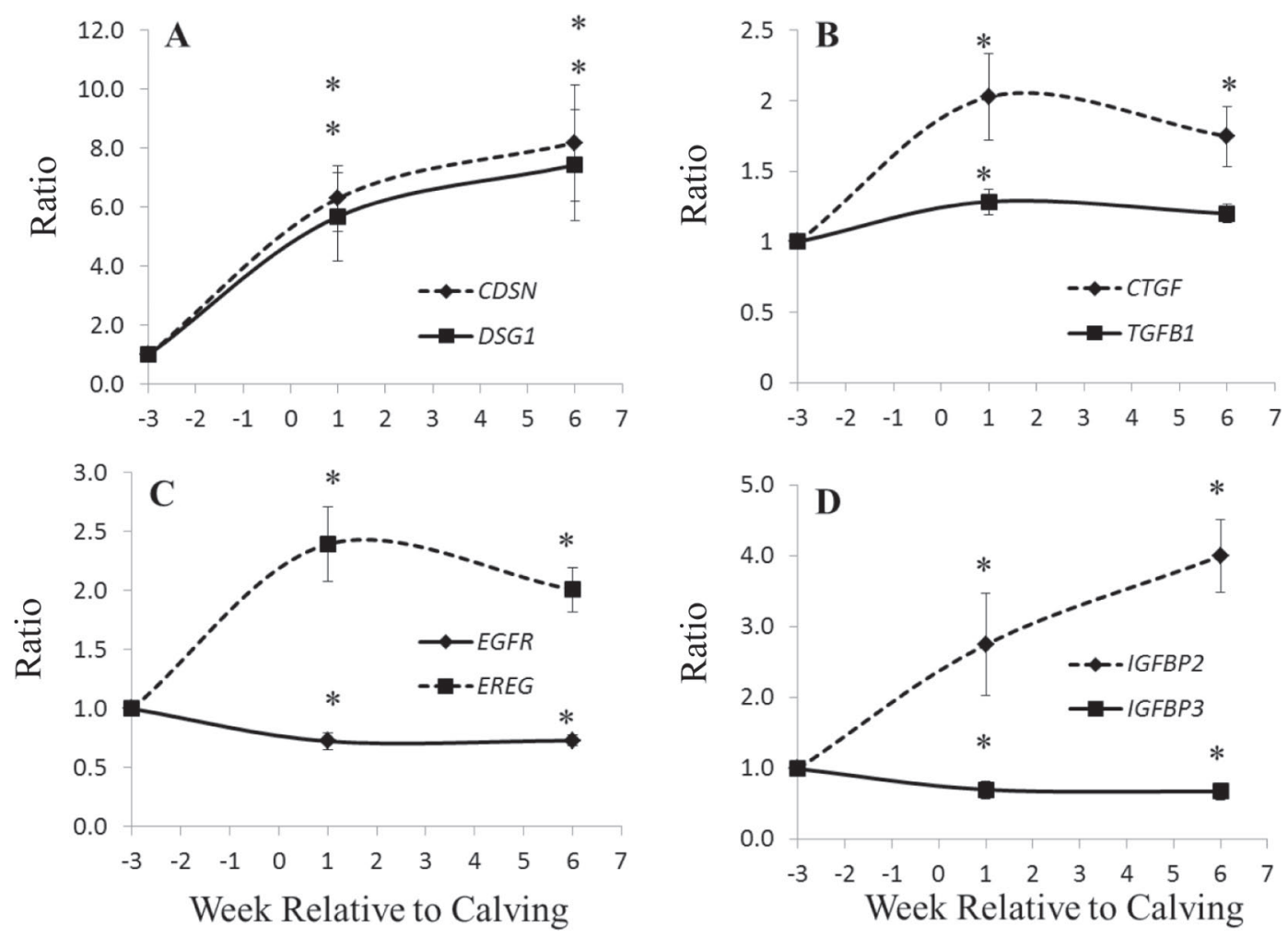

Figure 2. Quantitative real-time PCR results of candidate genes selected from microarray analysis from -3 to +1 and +6 wk relative to parturition $(\mathrm{n}=12)$. A) Upregulation of desmoglein1 (DSG1) and corneodesmosin $(C D S N)$, B) upregulation of connective tissue growth factor $(C T G F)$ and transforming growth factor $\beta 1$ (TGFB1), C) upregulation of epiregulin (EREG) and downregulation of epidermal growth factor receptor $(E G F R)$, and D) upregulation of IGF binding protein 2 (IGFBP2) and downregulation of IGF binding protein $3\left(\right.$ IGFBP3; ${ }^{*} P<0.05$, significant difference from $-3 \mathrm{wk})$. Error bars represent SE.

\section{DISCUSSION}

The nutritional strategies to maximize milk production and health in early lactation are continually evolving (Drackley, 1999; Overton and Waldron, 2004). Traditionally, dairy cows were fed higher energy diets in the weeks before parturition to adapt the rumen in hopes of easing the transition to the higher energy lactating dairy cow diet (Vandehaar et al., 1999). Over the last decade, many studies have reported the benefits of feeding lower energy diets to dry cows up to parturition to avoid the risk of fatty liver and ketosis (Drackley et al., 2007). Although the benefits of controlling caloric intake prepartum to avoid overconditioning are well established (Douglas et al., 2006), the abrupt transition from a low-energy dry cow diet to a high-energy lactating cow diet may make the cow susceptible to digestive disorders such as ruminal acidosis (Plaizier et al., 2008). Moreover, it is not known how rumen papillae adapt during the transition; therefore, the overall objective of the current study was to survey the histological, morphological, and transcriptomic adaptations of the rumen papillae during early lactation.
In the current study, the DMI between -3 wk (13.1 $\pm 0.8 \mathrm{~kg}$ of $\mathrm{DM})$ to $+1 \mathrm{wk}(12.8 \pm 0.8 \mathrm{~kg}$ of $\mathrm{DM})$ were not different $(P>0.05$; Dionissopoulos et al., 2014). As expected, the DMI increased $(P<0.01)$ from both -3 wk and +1 to $+6 \mathrm{wk}(21.0 \pm 0.8 \mathrm{~kg}$ of DM). Ruminal $\mathrm{pH}$ and SCFA concentrations have been previously reported by Dionissopoulos et al. (2014). In brief, mean ruminal $\mathrm{pH}$ was reduced $(P<0.01)$ from $-3 \mathrm{wk}(6.38 \pm$ $0.08)$ to $+1 \mathrm{wk}(5.81 \pm 0.08)$ and $+6 \mathrm{wk}(5.85 \pm 0.08)$ relative to parturition. Correspondingly, as reported previously for these cows (Dionissopoulos et al., 2014), ruminal propionate, butyrate, isovalerate, and valerate concentrations were increased $(P<0.01)$ at +1 and +6 wk, resulting in an increase in total ruminal SCFA.

No differences in the living epithelial thickness (strata basale, spinosum, and granulosum) were detected at the base and mid-point of the papillae. In a similar study (Bannink et al., 2012), the rumen papillae of transition cows with a slow or fast introduction to concentrate were compared using histmorphometrics. Of the 5 regions studied, the dorsal sac was the only region of the rumen where thinning of the living strata occurred (Bannink et al., 2012). However, in the current study 


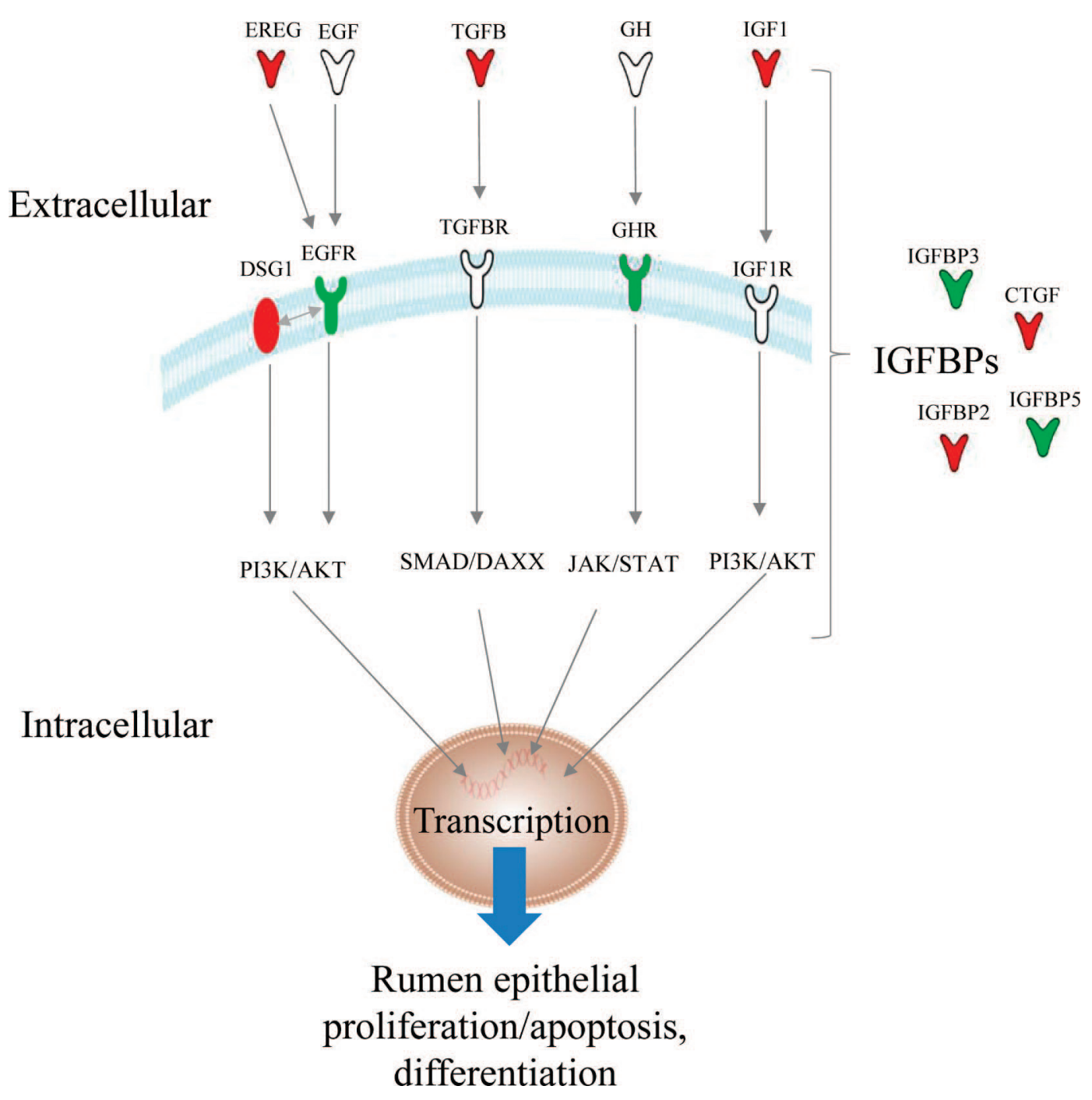

Figure 3. Illustrative representation of the relative difference $(P<0.05)$ in the mRNA content of genes related to growth factor signaling in rumen papillae of transition cows $(\mathrm{n}=12)$. Red symbols denote increased mRNA content from the dry period to early lactation, whereas green denotes decreased mRNA content from the dry period to early lactation. White denotes no detectable modulation $(P>0.05)$.

an increase in RE thickness at the tip of the papillae was found from the dry period to the first and sixth week of lactation. This may reflect a more accelerated rate of proliferation toward the tips of rumen papillae; however, very little is known about rumen papillae morphological growth.

The microscopic data in the present study clearly indicated a dramatic change in the histology and morphology of the RE during the onset of lactation and change in diet - in particular, accelerated cellular differentiation and desquamation of keratinocytes. Intermediate cells in the RE between the granulosum indicative of stratum lucidum were originally described by Dobson et al. (1956). Similarly, an increase in the number of cells in transition between the granulosum and corneum of the RE was recently observed in lambs (Steele et al., 2012) and dairy cattle (Steele et al., 2011a) during the shift from a low- to high-grain diet. Although accelerated differentiation and sloughing was evident in early lactation, based on histological examination the RE did not display lesions or any noticeable differences between cellular adhesion in the living strata between lactating and nonlactating cattle. The adhesion of cells in the RE was not impaired, a finding that contrasts with previous studies in ruminants using short-and long-term grain-induced acidosis challenges (Steele et al., 2009, 2011a).

The adaption to lactation was marked by several cell junction genes being differentially regulated during the onset of lactation (Supplemental Table S3; http:// 
dx.doi.org/10.3168/jds.2014-8640). Prior to the current study, only one experiment has shown that cell adhesion genes are regulated in the RE. Liu et al. (2013) reported that the transition from low to high energy diets is linked to the downregulation of $C L D N 1,4$, and occludin, yet the expression of these genes in the current study was not affected. Two of the largest fold changes in both microarray comparisons in the current study were for desmoglein 1 (DSG1) and corneodesmosin $(\boldsymbol{C D S N})$ - both desmosomal cadherins in the stratum granulosum and corneum of stratified squamous epithelium (SSE; Green and Jones, 1996). Corneodesmosin differential expression was a novel finding for the RE but not to the overall field of SSE. It has a critical role in the maturation of the cornified layer as the protein undergoes a series of cleavages, which are thought to be steps in desquamation (Simon et al., 2001). Desmoglein 1, which was also upregulated at both time points after parturition, is known to be highly expressed in the granulosum of SSE (Green and Simpson, 2007). Although DSG1 expression displayed the largest fold change in the current experiment and a previous microarray experiment in $\mathrm{RE}$, it was downregulated in the RE during a grain challenge, which is in contrast to the current study (Steele et al., 2011a). One reason for this finding may be explained through recent literature showing that in addition to cell adhesion, desmosomal cadherins are also involved in growth and differentiation (Cavallaro and Dejana, 2011). The dual function of cell adhesion genes may be relevant to RE biology.

\section{Growth Factors}

Understanding the mechanisms that orchestrate epithelial growth and differentiation may lead to future nutritional technologies for improving dairy cow health and production during early lactation. For example, cows are more susceptible to an accumulation of ruminal SCFA in early lactation (Plaizier et al., 2008). One possible strategy to compensate is to stimulate $\mathrm{RE}$ growth in early lactation, thereby increasing the surface area for SCFA absorption, potentially reducing low $\mathrm{pH}$-induced damage to $\mathrm{RE}$ and improving energy balance during early lactation. Screening for growth factors expressed in RE during the onset of lactation may provide a better understanding of the mechanisms controlling the adaptive growth response of the $\mathrm{RE}$ in early lactation. The results from the present study support previous findings that EGF, IGF-axis (Penner et al., 2011), and TGFB (Connor et al., 2014) families of growth factors are involved in RE growth and differentiation in a variety of experimental models in calves and cows.

\section{Epidermal Growth Factor}

The actions of EGF have been implicated as proliferative, differentiation, and healing agents in numerous tissues, including gastric and intestinal mucosa in rodents, pigs, and humans (Playford et al., 1993; Bazley and Gullick, 2005). An in vitro study with primary cultures of rumen cells indicated that EGF was a potent stimulant of RE proliferation (Baldwin, 1999). However, the regulation of this gene network via mRNA has not been detected by RE in vivo experimental models before the present study (Penner et al., 2011; Steele et al., 2011a). Epidermal growth factor binds to EGFR to elicit the signal transduction response (Figure 3). Like most growth factor receptors, EGFR has 10 ligands in addition to EGF, including TGFo and EREG (Herbst, 2004; Bazley and Gullick, 2005). In the present study, microarray analysis identified, and qPCR analysis validated that $E R E G$ was upregulated during early lactation. In keratinocytes, an increase in $E R E G$ expression induced autocrine growth factors to increase differentiation (Shirakata et al., 2000). In contrast to $E R E G$, the mRNA expression of EGFR was reduced in early lactation. In the stratified squamous epithelium of skin, EGFR signaling plays a major role in regulating keratinocyte proliferation, and downregulation of $E G F R$ signaling has been observed in skin disorders such as psoriasis, squamous cell carcinoma, and melanoma (Bektas et al., 2013). A reduction in the expression may be an adaptive response by RE to shift away from EGFR-mediated signal transduction pathways or regulate growth factors that are overexpressed (EREG).

As stated previously, cell adhesion molecules have also been shown to affect growth factor signaling. An example of such adhesion was recently reported by Getsios et al. (2009). In the current experiment, a mutant version of $D S G 1$ lacking properties for cell adhesion was still able to induce keratinocyte differentiation via EGF signal transduction pathways. Moreover, EGFR and $D S G 1$ colocalize on the cell membrane of keratinocytes, yet the precise molecular based mechanism of interaction is not understood (Getsios et al., 2009; Figure 3). The upregulation of DSG1 in the RE may be activating the downstream events of EGF signaling independent of EGFR. This also may be another explanation for the downregulation of $E G F R$ expression in early lactation, due to the overexpression of $D S G 1$.

\section{IGF Axis}

In dairy cows, blood GH is elevated in early lactation and the liver GHR gene expression decreases after calving, thereby decreasing IGF-1 in circulation (uncoupling 
the IGF axis). Improved energy balance may increase the GHR expression and IGF-I, and reduce GH concentrations as cows approach the breeding period. It was noted in the present experiment that the expression of GHR was downregulated during the onset of lactation, possibly to compensate for higher $\mathrm{GH}$ concentration in circulation in early lactation (Radcliff et al., 2003). As such, this is the first report that GHR expression is regulated in $\mathrm{RE}$.

With a very short half-life, GH action is mostly mediated by GH-dependent hepatic production of IGF-1. The current study was marked by an increase in expression of IGF1 and $5 I G F B P$ mRNA during the first and sixth week of lactation. The effect that IGF-1 has on RE proliferation and growth has been known for several decades (Sakata et al., 1980). Studies conducted with primary RE cells, such as EGF, showed a potent stimulatory effect of IGF-1 (Baldwin, 1999). Shen et al. (2004) were the first to report differential gene expression related to IGF-1 as the transition from a lowenergy to higher energy diets in goats was associated with an increase in the expression of IGF-1 receptor. In line with this finding, Connor et al. (2014) conducted a study comparing rumen tissue from milk- and grain-fed calves and found through IPA network analysis that $I G F 1 R$ was a key transcriptional regulator for the observed treatment differences. Furthermore, Naeem et al. (2012) reported that IGF1 and INSR mRNA expression is increased in rumen tissue in response to higher planes of nutrition being fed preweaning.

Cellular events of IGF1 are modulated by IGFBP in tissues, and in the present study, a total of 5 IGFBP were determined to be regulated during early lactation (IGFBP2, 3, 5, 7, and CTGF). The effects of IGFBP can be independent of IGF1 concentrations, as SCFA have been shown to alter IGFBP expression (Sanderson, 2004). It is well documented that specific IGFBP stimulate, whereas others impede IGF events. Because $I G F B P 3$ is well-known to block IGF1 events, the reduced expression of IGFBP3 makes biological sense and corresponds to other reports in mature dairy cattle transitioned to high-grain diets (Steele et al., 2011a,b, 2012). The expression of IGFBP3 also was downregulated during early lactation, consistent with previous findings that it is downregulated in mature dairy cattle during a grain challenge (Steele et al., 2011a). The differential expression of IGFBP2, 7 by the $\mathrm{RE}$ is the first report that these IGF event-stimulating growth factors (Hwa et al., 1999) are expressed by RE. The $C T G F$, which is defined as an $I G F B P$, was also shown to be upregulated and controls the expression of other growth factors such as TGFB (Grotendorst, 1997). Collectively, these results further support the notion that the IGF-axis may be involved in the adaptation of
RE during early lactation through a highly integrated regulation of growth factors.

\section{Transforming Growth Factor $\beta$}

The transforming growth factor $\beta$ superfamily of growth factors controls a variety of cellular processes including cell proliferation, recognition, differentiation, and apoptosis (Shi and Massague, 2003; Krishnan et al., 2011). Three isoforms are present during development and have distinct overlapping expression patterns (Govinden and Bhoola, 2003). It was recently found that TGFB1 is regulated in grain induced ruminal development in dairy calves (Connor et al., 2014). In contrast, TGFB1 was shown to be downregulated in lactating dairy cattle infused with butyrate (Baldwin et al., 2012). The discrepancy found in TGFB1 mRNA expression responses between growing versus adult cows may be due in part to differences in the functions of TGFB1 in calf versus adult RE. For instance, TGFB1 inhibits cell proliferation, enhances apopotosis, and promotes cellular differentiation (Govinden and Bhoola, 2003). In the present study, both TGFB1 and TGFB2 and their subfamily of bone morphogenetic proteins (Krishnan et al., 2011) were upregulated during the onset of lactation. For each microarray comparison, networks revolved around TGFB1 (Supplemental Figures S3 and S5; http://dx.doi.org/10.3168/jds.20148640). This understanding supports the recent finding (Connor et al., 2014) that TGFB1 may be involved in regulating growth and differentiation in the $\mathrm{RE}$ in early lactation.

Identifying growth factor signaling that was responsive to the onset of lactation was an important objective of the current study. Understanding what specific growth factors control RE growth and differentiation could be important in the selection of rations or bioactive ingredients to feed to cattle to induce targeted $\mathrm{RE}$ growth and differentiation. A key time would be to initiate growth in early lactation to increase surface area of absorption of SCFA. It has been established that the rumen mass grows by $55 \%$ in the first 4 mo of lactation (Baldwin et al., 2004), albeit the rate of these changes are not known. Development of feeding strategies that increase the rate of rumen epithelial growth may result in an increased capacity to absorb more SCFA in early lactation, thereby improving energy balance and reducing the risk of ruminal acidosis.

\section{CONCLUSIONS}

Prior to the current study, most transition dairy cow research has focused on elucidating the molecular mechanisms of liver, fat, muscle, and mammary gland 
metabolism. However, the present study using a typical production regimen has revealed that the rumen tissue of the dairy cattle also undergoes adaptations, including accelerated cell differentiation and sloughing of the corneum. With respect to the mRNA expression data, candidate genes and networks involved in cell junctions, and an array of growth factors (TGF, EGF, IGF-axis) were regulated in early lactation. Furthermore, the transcriptomic data showcases that growth factors with distinct, nonredundant biological functions orchestrate the response. Overall, the experimental data supported the hypothesis that rumen papillae adapt in early lactation by altering their gene expression patterns, and thus, their epithelial structure.

\section{REFERENCES}

Baldwin, R. L. VI 1999. The proliferative actions of insulin, insulinlike growth factor-I, epidermal growth factor, butyrate and propionate on ruminal epithelial cells in vitro. Small Rumin. Res. $32: 261-268$.

Baldwin, R. L. VI, K. R. McLeod, and A. V. Capuco. 2004. Visceral tissue growth and proliferation during the bovine lactation cycle. J. Dairy Sci. 87:2977-2986.

Baldwin, R. L. VI, S. Wu, W. Li, C. Li, B. J. Bequette, and R. W. Li. 2012. Quantification of transcriptome responses of the rumen epithelium to butyrate infusion using RNA-seq technology. Gene Regul. Syst. Biol. 6:67-80.

Bannink, A., W. J. J. Gerrits, J. France, and J. Dijkstra. 2012. Variation in rumen fermentation and the rumen wall during the transition period in dairy cows. Anim. Feed Sci. Technol. 172:80-94.

Bazley, L. A., and W. J. Gullick. 2005. The epidermal growth factor receptor family. Endocr. Relat. Cancer 12:S17-S27.

Bektas, M., P. S. Jolly, P. Berkowitz, M. Amagai, and D. S. Rubenstein. 2013. A pathophysiologic role for epidermal growth factor receptor in pemphigus acantholysis. J. Biol. Chem. 288:9447-9456.

Canadian Council on Animal Care. 1993. Guide to the Care and Use of Experimental Animals. The Council, Ottawa, Canada.

Cavallaro, U., and E. Dejana. 2011. Adhesion molecule signalling: Not always a sticky business. Nat. Rev. Mol. Cell Biol. 12:189-197.

Connor, E. E., R. L. Baldwin VI, M. P. Walker, S. E. Ellis, C. Li, S. Kahl, H. Chung, and R. W. Li. 2014. Transcriptional regulators transforming growth factor- $\beta 1$ and estrogen-related receptor- $\alpha$ identified as putative mediators of calf rumen epithelial tissue development and function during weaning. J. Dairy Sci. 97:41934207.

Dionissopoulos, L., O. AlZahal, M. A. Steele, J. C. Matthews, and B. W. McBride. 2014. Transcriptomic changes in ruminal tissue induced by the periparturient transition in dairy cows. Am. J. Anim. Vet. Sci. 9:36-45.

Dobson, M. J., W. C. B. Brown, A. Dobson, and A. T. Phillipson. 1956. A histological study of the organization of the rumen epithelium of sheep. Q. J. Exp. Physiol. Cogn. Med. Sci. 41:247-253.

Douglas, G. N., T. R. Overton, H. G. Bateman II, H. M. Dann, and J. K. Drackley. 2006. Prepartal plane of nutrition, regardless of dietary energy source, affects periparturient metabolism and dry matter intake in Holstein cows. J. Dairy Sci. 89:2141-2157.

Drackley, J. K. 1999. Biology of dairy cows during the transition period: The final frontier? J. Dairy Sci. 82:2259-2273.

Drackley, J. K., B. C. Pollard, H. M. Dann, and J. A. Stamey. 2007. First-lactation milk production for cows fed control or intensified milk replacer programs as calves. J. Dairy Sci. 90(Suppl. 1):614. (Abstr.)

Duffield, T. F. 1999. A fistful of rumen - A novel approach to rumen fistula surgery. Proc. Am. Assoc. Bovine Pract. 32:179.
Gäbel, G., J. R. Aschenbach, and F. Müller. 2002. Transfer of energy substrates across the ruminal epithelium: Implications and limitations. Anim. Health Res. Rev. 3:15-30.

Getsios, S., C. L. Simpson, S. Kojima, R. Harmon, L. J. Sheu, R. L. Dusek, M. Cornwell, and K. J. Green. 2009. Desmoglein 1-dependent suppression of EGFR signaling promotes epidermal differentiation and morphogenesis. J. Cell Biol. 185:1243-1258.

Govinden, R., and K. D. Bhoola. 2003. Genealogy, expression, and cellular function of transforming growth factor-I. Pharmacol. Ther. 98:257-265.

Graham, C., and N. L. Simmons. 2005. Functional organization of the bovine rumen epithelium. Am. J. Physiol. Regul. Integr. Comp. Physiol. 288:R173-R181.

Green, K. J., and J. C. R. Jones. 1996. Desmosomes and hemidesmesomes: Structure and function of molecular components. FASEB J. $10: 871-881$.

Green, K. J., and C. L. Simpson. 2007. Desmosomes: New perspective on a classic. J. Invest. Dermatol. 127:2499-2515.

Grotendorst, G. R. 1997. Connective tissue growth factor: A mediator of TGF-beta action on fibroblasts. Cytokine Growth Factor Rev. $8: 171-179$.

Herbst, R. S. 2004. Review of epidermal growth factor receptor biology. Int. J. Radiat. Oncol. Biol. Phys. 59:21-26.

Hwa, V., O. Youngman, and R. G. Rosenfeld. 1999. The insulin-like growth factor-binding protein (IGFBP) superfamily. Endocr. Rev. 20:761-787.

Krishnan, K., B. Arnone, and A. Buchman. 2011. Intestinal growth factors: Potential use in the treatment of inflammatory bowel disease and their role in mucosal healing. Inflamm. Bowel Dis. $17: 410-422$

Liu, J., T. Xu, Y. Liu, W. Zhu, and S. Mao. 2013. A high-grain diet causes massive disruption of ruminal epithelial tight junctions in goats. Am. J. Physiol. Regul. Integr. Comp. Physiol. 305:R232R241.

Naeem, A., J. K. Drackley, J. Stamey, and J. J. Loor. 2012. Role of metabolic and cellular proliferation genes in ruminal development in response to enhanced plane of nutrition in neonatal Holstein calves. J. Dairy Sci. 95:1807-1820.

NRC. 2001. Nutrient Requirements of Dairy Cattle. 7th rev. ed. Natl. Acad. Press, Washington, DC.

Odongo, N. E., O. AlZahal, M. I. Lindinger, T. F. Duffield, E. V. Valdes, S. P. Terrell, and B. W. McBride. 2006. Effects of mild heat stress and grain challenge on acid-base balance and rumen tissue histology in lambs. J. Anim. Sci. 84:447-455.

Overton, T. R., and M. R. Waldron. 2004. Nutritional management of transition dairy cows: Strategies to optimize metabolic health. J. Dairy Sci. 87:E105-E119.

Penner, G. B., M. A. Steele, J. R. Aschenbach, and B. W. McBride. 2011. Molecular adaptation of ruminal epithelia to highly fermentable diets. J. Anim. Sci. 89:1108-1119.

Pfaffl, M. W. 2001. A new mathematical model for relative quantification in real-time RT-PCR. Nucleic Acids Res. 29:e45.

Plaizier, J. C., D. O. Krause, G. N. Gozho, and B. W. McBride. 2008. Subacute ruminal acidosis in dairy cows: The physiological causes, incidence and consequences. Vet. J. 176:21-31.

Playford, R. J., A. C. Woodman, D. Vesey, P. H. Deprez, J. Calam, P. Watanapa, R. C. N. Williamson, and P. Clark. 1993. Effect of luminal growth factor preservation on intestinal growth. Lancet 341:843-848.

Radcliff, R. P., B. L. McCormack, B. A. Crooker, and M. C. Lucy. 2003. Plasma hormones and expression of growth hormone receptor and insulin-like growth factor-I mRNA in hepatic tissue of periparturient dairy cows. J. Dairy Sci. 86:3920-3926.

Rémond, D., I. Ortigues, and J. Jouany. 1995. Energy substrates for the rumen epithelium. Proc. Nutr. Soc. 54:95-105.

Sakata, T., K. Hikosaka, Y. Shiomura, and H. Tamate. 1980. Stimulatory effect of insulin on ruminal epithelium cell mitosis in adult sheep. Br. J. Nutr. 44:325-331.

Sakata, T., and H. Tamate. 1978. Rumen epithelial cell proliferation accelerated by rapid increase in intraruminal butyrate. J. Dairy Sci. $61: 1109-1113$. 
Sanderson, I. R. 2004. Short chain fatty acid regulation of signaling genes expressed by the intestinal epithelium. J. Nutr. 134:2450S$2454 \mathrm{~S}$.

SAS Institute Inc. 2004. SAS/STAT Users Guide. Release 9.1. SAS Inst. Inc., Cary, NC.

Shen, Z., H. M. Seyfert, B. Löhrke, F. Schneider, R. Zitnan, A. Chudy, S. Kuhla, H. A. Hammon, J. W. Blum, H. Martens, H. Hagemeister, and J. Voigt. 2004. An energy-rich diet causes rumen papillae proliferation associated with more IGF type 1 receptors and increased plasma IGF-1 concentrations in young goats. J. Nutr. 134:11-17.

Shi, Y., and J. Massague. 2003. Mechanisms of TGF-Î̃ ${ }^{2}$ signaling from cell membrane to the nucleus. Cell 113:685-700.

Shirakata, Y., T. Komurasaki, H. Toyoda, Y. Hanakawa, K. Yamasaki, S. Tokumaru, K. Sayama, and K. Hashimoto. 2000. Epiregulin, a novel member of the epidermal growth factor family, is an autocrine growth factor in normal human keratinocytes. J. Biol. Chem. 275:5748-5753.

Simon, M., N. Jonca, M. Guerrin, M. Haftek, D. Bernard, C. Caubet, T. Epelrud, R. Schmidt, and G. Serre. 2001. Corneodesmosin proteolysis during terminal differentiation of human epidermis and its relationship to desquamation. J. Biol. Chem. 276:20292-20299.

Steele, M. A., O. AlZahal, S. L. Greenwood, J. C. Matthews, and B. W. McBride. 2013. Technical note: Use of laser capture microdissection for the localization of tissue-specific global gene expression in rumen papillae. J. Dairy Sci. 96:7748-7752.

Steele, M. A., O. AlZahal, S. E. Hook, J. Croom, and B. W. McBride. 2009. Ruminal acidosis and the rapid onset of ruminal parakeratosis in a mature dairy cow: A case report. Acta Vet. Scand. 51:39.
Steele, M. A., J. Croom, M. Kahler, O. AlZahal, S. E. Hook, K. Plaizier, and B. W. McBride. 2011a. Bovine rumen epithelium undergoes dramatic structural adaptations during grain-induced ruminal acidosis epithelial adaptation. Am. J. Physiol. Integr. Comp. Phys. 300:R1515-R1523.

Steele, M. A., S. L. Greenwood, J. Croom, and B. W. McBride. 2012. An increase in dietary non-structural carbohydrates alters the structure and metabolism of the rumen epithelium in lambs. Can. J. Anim. Sci. 92:123-130.

Steele, M. A., G. Vandervoort, O. AlZahal, S. E. Hook, J. C. Matthews, and B. W. McBride. 2011b. Rumen epithelial adaptation to high-grain diets involves the coordinated regulation of genes involved in cholesterol homeostasis. Physiol. Genomics 43:308-316.

Vandehaar, M. J., G. Yousif, B. K. Sharma, T. H. Herdt, R. S. Emery, M. S. Allen, and J. S. Liesman. 1999. Effect of energy and protein density of prepartum diets on fat and protein metabolism of dairy cattle in the periparturient period. J. Dairy Sci. 82:1282-1295.

Von Engelhardt, W., and J. R. S. Hales. 1977. Partition of capillary blood flow in rumen, reticulum, and omasum of sheep. Am. J. Physiol. 232:E53.

Xue, Y., S. F. Liao, K. W. Son, S. L. Greenwood, B. W. McBride, J. A. Boling, and J. C. Matthews. 2010. Metabolic acidosis in sheep alters expression of renal and skeletal muscle amino acid enzymes and transporters. J. Anim. Sci. 88:707-717.

Ye, J., G. Coulouris, I. Zaretskaya, I. Cutcutache, S. Rozen, and T. Madden. 2012. Primer-BLAST: A tool to design target-specific primers for polymerase chain reaction. BMC Bioinformatics $13: 134$. 